\title{
Influence of various aromatic derivatives on the advanced photo Fenton degradation of Amaranth dye
}

\author{
L. Gomathi Devi*, K. Eraiah Rajashekhar, K.S. Anantha Raju, S. Girish Kumar \\ Department of Post Graduate Studies in Chemistry, Central College Campus, Dr. B. R. Ambedkar Veedi, Bangalore University, Bangalore-560 001, India
}

\section{A R T I C L E I N F O}

Article history:

Received 5 January 2010

Received in revised form 5 November 2010

Accepted 5 November 2010

Available online 9 December 2010

\section{Keywords:}

Zero-valent metallic iron

Photo Fenton process

Aromatic derivatives

Ammonium persulfate

Kinetic studies

\begin{abstract}
A B S T R A C T
The photo degradation of Amaranth (AR) dye by advanced photo Fenton process in the presence of symmetrical peroxides like hydrogen peroxide $\left(\mathrm{H}_{2} \mathrm{O}_{2}\right)$ and ammonium persulfate (APS) are investigated. The influence of various reaction parameters like the effect of iron dosage, concentration of $\mathrm{H}_{2} \mathrm{O}_{2} / \mathrm{APS}$, initial dye concentration, effect of $\mathrm{pH}$ and the influence of various aromatic derivatives were studied and optimum conditions are reported. The efficiency of the oxidant was strongly influenced by the nature of aromatic photoproducts formed during the course of the degradation reaction. To study their effect on the rate of degradation these aromatic derivatives were added in known concentration (10 ppm). The influence of various aromatic derivatives on the degradation kinetics shows the following order: hydroquinones $>$ chlorophenol $>$ dichlorobenzene $>$ aromatic carboxylic acids $>$ anilidine $>$ nitrophenol. The addition of these derivatives did not influence the degradation pathway although it altered the reaction rate. The percentage COD and TOC removal were determined in presence of aromatic derivatives to evaluate the complete removal of the pollutant. Based on the intermediates obtained in the UV-vis and GC-MS spectroscopic techniques probable degradation mechanism has been proposed.
\end{abstract}

(c) 2010 Elsevier B.V. All rights reserved.

\section{Introduction}

Zero-valent metallic iron (ZVMI) has been used as a potential catalyst for the efficient production of hydroxyl radicals in Fenton/ photo-Fenton process to degrade many pollutants [1-6]. The homogeneous Fenton and photo Fenton process have also been widely used for the degradation of organic contaminants [7-11]. Many researchers have investigated the applications of iron incorporated zeolities (sodium-alumino silicates) [12], ferihydrite, crystalline goethite [13] and semi crystalline Iron oxide [14] as catalytic material for the oxidation of organic pollutants. Lucking et al. [15] tested the catalytic properties of iron powder, graphite and activated carbon for the oxidation of 4-chlorophenol in aqueous solution with hydrogen peroxide. They concluded that fine metallic iron powder could be used to replace the iron salts as a catalyst in the Fenton reactions. From the environmental point of view, the advantage of using ZVMI instead of iron salts is that, the concentration of the iron ions in the wastewater after the treatment can be significantly reduced. Moreover, use of ZVMI as catalyst instead of iron salts prevents the additional anion loading in the treatment of wastewater. The residual iron powder can be easily removed after the treatment and can be easily recycled [10]. The efficiency of the Fenton process critically depends on the regeneration of ferrous ions in the solution. Any reaction that promotes the reduction of $\mathrm{Fe}^{3+}$ ions would accelerate the Fenton

\footnotetext{
* Corresponding author. Tel.: +91 80 22961336; fax: +91 8022961331 . E-mail address: gomatidevi_naik@yahoo.co.in (L. Gomathi Devi).
}

reaction. In this regard, ZVMI is used as a source of $\mathrm{Fe}^{2+}$ ions in the photo Fenton process. The higher activity of ZVMI was attributed to the faster reduction of $\mathrm{Fe}^{3+}$ ions on the iron surface [16,17].The addition of oxalic acid and aromatic derivative like hydroquinone was found to have catalytic action for the reduction of $\mathrm{Fe}^{3+}$ ions (Eq. 1) thereby accelerating the reaction [18-20]. Since most of the dye waste water contains various aromatic phenolic compounds, a detailed study of their influence on the photo Fenton process would be of great importance. In view of this, we report the degradation of Amaranth (AR) influenced by the presence of various kinds of aromatic phenol derivatives, the effect of oxidant concentration, catalyst loading, effect of $\mathrm{pH}$, influence of hydroxyl radical scavenger and the initial concentration of the dye on the degradation rate using ZVMI as the catalyst in the Photo-Fenton process. Though $\mathrm{H}_{2} \mathrm{O}_{2}$ is extensively used in Fenton's process, very few attempts have been made towards the use of peroxy disulfate as an oxidant. In view of this, the main focus is on two aspects i) influence of aromatic derivatives on the rate and mechanism of photodegradation of AR, and ii) utilization of ammonium persulfate (APS) which is also a symmetrical peroxide like hydrogen peroxide in the Fenton's and photo-Fenton's process.

\section{Materials and methods}

\subsection{Materials}

Amaranth (AR), iron powder (100 mesh size, electrolytic), ammonium persulfate (APS), hydrogen peroxide (50\%), $\mathrm{NaCl}, \mathrm{Na}_{2} \mathrm{SO}_{4}$, Catechol ( $\mathrm{CH})$, Resorcinol (RH), Hydroquinone (HQ), p-chloro phenol 
(p-CP), p-amino phenol (p-AP), p-nitro phenol (p-NP), p-dichloro benzene (p-DCB), Salicylic acid (SA), Benzoic acid (BA), Pthalic acid $(\mathrm{PA})$, Aniline (AN) and aliphatic derivatives like Oxalic acid (OA), Methyl alcohol $(\mathrm{MeOH})$ and iso-propyl alcohol (iPrOH) were obtained from SD Fine Chemicals Bombay. The molecular formula of AR is $\mathrm{C}_{20} \mathrm{H}_{11} \mathrm{~N}_{2} \mathrm{Na}_{3} \mathrm{O}_{10} \mathrm{~S}_{3}$ (M. W = 604.48) and has $\lambda_{\text {max }}$ at $521 \mathrm{~nm}$. The structure of the dye is shown in the Fig. 1.

\subsection{Irradiation procedure}

All the photoreactions were carried out at room temperature using a circular glass reactor whose surface area is $176.6 \mathrm{~cm}^{2}$. The reactor was placed in a thermostat at a temperature of $298 \pm 5 \mathrm{~K}$. Artificial light source used in the present study is $125 \mathrm{~W}$ medium pressure mercury vapour lamp. The photon flux of the light source is $8.75 \mathrm{~mW} / \mathrm{cm}^{2}$ as determined by ferri oxalate actinometry, the wavelength of which peaks around $370 \mathrm{~nm}$. In a typical experiment, $200 \mathrm{mg} / \mathrm{L}$ of the AR dye solution is taken in the reactor along with desired amount of iron powder ( $50 \mathrm{mg} / \mathrm{L}$ ) and oxidants (APS $=100 \mathrm{mg} / \mathrm{L}$ or $\mathrm{H}_{2} \mathrm{O}_{2}=50 \mathrm{mg} / \mathrm{L}$ ). The reaction involving the presence of aromatic derivatives was carried out at $10 \mathrm{ppm}$ concentration. The lamp was warmed for $10 \mathrm{~min}$ to reach constant output. The irradiation was carried out by direct focusing the light into the reaction mixture in open air condition at a distance of $29 \mathrm{~cm}$. All the experiments were performed using double distilled water. $\mathrm{pH}$ of the solution was adjusted either by adding dilute $\mathrm{NaOH}$ or $\mathrm{H}_{2} \mathrm{SO}_{4}$.

\subsection{Analytical methods}

A reaction mixture of $5 \mathrm{ml}$ is taken out from the reactor at definite time intervals and it is centrifuged. The centrifugates were analyzed by UV-visible spectroscopic technique using Shimadzu UV-1700 Pharmaspec UV-visible spectrophotometer. The centrifugates were extracted into non-aqueous ether medium and $1 \mu \mathrm{L}$ was subjected to GC-MS analysis (using GC-MS-QP-5000 Shimadzu) and Thermo Electron Trace GC ultra coupled to a DSQ mass spectrometer equipped with an Alltech ECONO-CAP-EC-5 capillary column (30 m $\times 0.25 \mathrm{~mm}$ i.d $\times 0.25 \mathrm{~mm}$ film thickness) was used. Pure helium was used as the carrier gas at a flow rate of $1.2 \mathrm{ml} / \mathrm{min}$. The injector/transfer line/trap temperature was $220 / 250 / 200{ }^{\circ} \mathrm{C}$ respectively. Electron impact ionization was carried out at $70 \mathrm{eV}$. Total Organic Carbon (TOC) content of dye and the added organic derivatives were monitored using Shimadzu TOC analyzer.

\section{Results and discussion}

\subsection{Comparison between Fenton and advanced photo-Fenton process}

The classical Fenton process involves aqueous Fe (II) ions with $\mathrm{H}_{2} \mathrm{O}_{2}$ to generate hydroxyl radicals which in turn degrade recalcitrant organic pollutants. The application of this process is limited by the amount of ferrous ion in the solution and the ability of the system to regenerate ferrous ions. The present research focuses on the

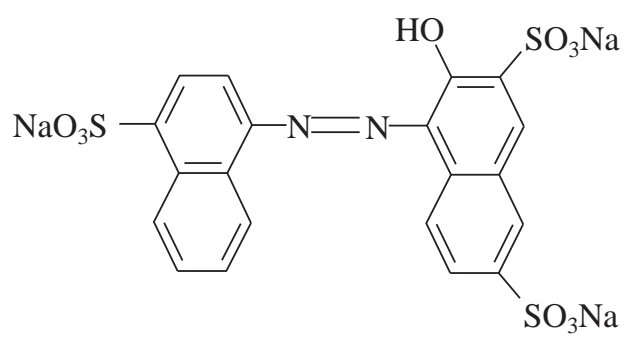

Fig. 1. Structure of $A R$ generation of hydroxyl radicals that differs from classical Fenton process by taking ZVMI. This application is referred to as Advanced Photo Fenton Process (APFP), which utilizes the metallic iron surfaces to generate $\mathrm{Fe}^{2+}$ ions and gives rise to potent Fenton type reactions. The $\mathrm{Fe}^{2+}$ ions so formed are further oxidized to $\mathrm{Fe}^{3+}$ in the presence of oxidizing agents. The reduction of $\mathrm{Fe}^{3+}$ ion to $\mathrm{Fe}^{2+}$ is faster at the iron surface compared to the homogeneous Fenton process as shown in Eq. (1) in Scheme 1. These factors attribute to the potential application of modified Fenton process [17]. ZVMI is readily oxidized to $\mathrm{Fe}^{2+}$ ion in the presence of oxidants. In the aqueous systems this phenomenon leads to the dissolution of solid which is the primary cause of metal corrosion. The various possible reactions of iron powder with $\mathrm{H}_{2} \mathrm{O}_{2} /$ APS are shown in Eqs. (2)-(16) in Scheme 1.

\subsection{Effect of catalyst loading}

The optimization of the catalyst is a necessary step in the photoFenton process. The percentage of degradation was found to be 78 and $64 \%$ when $\mathrm{H}_{2} \mathrm{O}_{2}$ and APS are used as oxidants for the catalyst loading of $50 \mathrm{mg} / \mathrm{L}$. The percentage of degradation decreases with further increase in the catalyst concentration as shown in Fig. 2. Increase in the dosage of catalyst not only decreases the percentage of degradation, it also changes the final pH of the solution from 3.5 to 4.4, leading to the yellow coloration. At this condition the reaction mixture turns turbid. On further increase in the catalyst loading $(75-100 \mathrm{mg} / \mathrm{L})$, excess iron precipitates as iron oxyhydroxide and the precipitate separates from the true solution and the $\mathrm{pH}$ of the solution changes to 4.9. High dosage of iron powder increases the concentration of $\mathrm{Fe}^{2+}$ ions in the solution which can also act as hydroxyl radical scavenger as shown by Eq. (16) in Scheme 1 [21]. The iron surface catalytically decomposes the oxidants to respective free radicals/ions more efficiently under UV light. On the contrary, over-loading of the catalyst hinders the degradation efficiency. This may be due to: (1) higher concentration of the catalyst results in turbidity which hinders the penetration of UV light [22]; and (2) with increase in the catalyst concentration, the final $\mathrm{pH}$ of the solution

$$
\begin{aligned}
& 2 \mathrm{Fe}^{3+}+\mathrm{Fe}^{0} \rightarrow 3 \mathrm{Fe}^{2+} \\
& \mathrm{Fe}^{0} \stackrel{\mathrm{H}^{+}}{\longrightarrow} \mathrm{Fe}^{2+} \\
& \mathrm{Fe}^{0}+\mathrm{H}_{2} \mathrm{O}_{2} \rightarrow \mathrm{Fe}^{2+}--- \text { Surface } \\
& \mathrm{Fe}^{2+}{ }_{--} \text {Surface }+\mathrm{H}_{2} \mathrm{O}_{2} \rightarrow \mathrm{Fe}^{3+}+\mathrm{OH}^{\cdot}+\mathrm{OH}^{-} \\
& \mathrm{Fe}^{0}+\mathrm{H}_{2} \mathrm{O}_{2} \rightarrow \mathrm{Fe}^{2+}+2 \mathrm{OH}^{-} \\
& \mathrm{Fe}^{0}+\mathrm{S}_{2} \mathrm{O}_{8}{ }^{2-} \rightarrow 2 \mathrm{SO}_{4}{ }^{2-}+\mathrm{Fe}^{2+} \\
& \mathrm{Fe}^{2+}+\mathrm{H}_{2} \mathrm{O}_{2} \rightarrow \mathrm{Fe}^{3+}+\mathrm{OH}^{\cdot}+\mathrm{OH}^{-} \\
& \mathrm{Fe}^{2+}+\mathrm{S}_{2} \mathrm{O}_{8}{ }^{2-} \rightarrow \mathrm{Fe}^{3+}+\mathrm{SO}_{4}{ }^{2-}+\mathrm{SO}_{4}{ }^{-} \\
& \mathrm{Fe}^{3+}+\mathrm{H}_{2} \mathrm{O} \leftrightarrow\left[\mathrm{Fe}(\mathrm{OH})^{2+}\right]+\mathrm{H}^{+} \\
& {\left[\mathrm{Fe}(\mathrm{OH})^{2+}\right]+\mathrm{h} \gamma \rightarrow \mathrm{Fe}^{2+}+\mathrm{OH}^{*}} \\
& \mathrm{Fe}^{3+}+\mathrm{H}_{2} \mathrm{O}_{2} \rightarrow \mathrm{Fe}^{2+}+\mathrm{O}_{2} \mathrm{H}^{\cdot}+\mathrm{H}^{+} \\
& \mathrm{Fe}^{3+}+\mathrm{O}_{2} \mathrm{H}^{\cdot} \rightarrow \mathrm{Fe}^{2+}+\mathrm{OH}^{\cdot} \\
& \mathrm{Fe}^{3+}+\mathrm{S}_{2} \mathrm{O}_{8}{ }^{2-} \rightarrow 2 \mathrm{SO}_{4}{ }^{-\cdot}+\mathrm{Fe}^{2+} \\
& \mathrm{SO}_{4}{ }^{-\cdot}+\mathrm{H}_{2} \mathrm{O} \rightarrow \mathrm{SO}_{4}{ }^{2-}+\mathrm{OH}^{\cdot}+\mathrm{H}^{+} \\
& \mathrm{H}^{+}+\mathrm{OH}^{\cdot}+\mathrm{e}^{-} \rightarrow \mathrm{H}_{2} \mathrm{O} \\
& \mathrm{Fe}^{2+}+\mathrm{OH}^{\cdot} \rightarrow \mathrm{Fe}^{3+}+\mathrm{OH}^{-}
\end{aligned}
$$

Scheme 1. Various possible reactions in the Fenton, Photo Fenton and Advanced Photo Fenton process. 


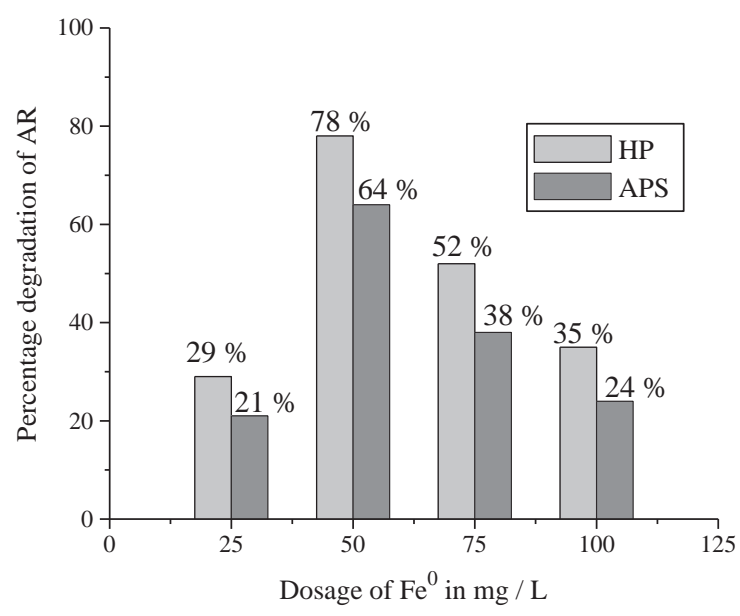

Fig. 2. Percentage removal of $A R$ with respect to dosage of $\mathrm{Fe}^{0}$ catalyst in presence of oxidants (HP/APS) under UV illumination for the experimental conditions of $[\mathrm{AR}]=$ $200 \mathrm{mg} / \mathrm{L},[\mathrm{HP}]=50 \mathrm{mg} / \mathrm{L} /[\mathrm{APS}]=100 \mathrm{mg} / \mathrm{L}$ at $\mathrm{pH} 3$.

increases, leading to the hydroxylation of the iron surface which in turn adversely affects the decolorization rate.

\subsection{Effect of initial concentration of oxidizing agents}

The present study investigates the application of $\mathrm{H}_{2} \mathrm{O}_{2}$ and APS which are symmetrical peroxides and can act as potential oxidants in the light induced reaction processes. Persulfate can generate free radicals like sulfate and hydroxyl radicals which provide free radical mechanism similar to hydroxyl radical pathways generated in the Fenton's chemistry. The sulfate radical is one of the strongest oxidizing species in aqueous media with a redox potential of $2.6 \mathrm{~V}$. It is next only to the hydroxyl free radical whose redox potential is $2.8 \mathrm{~V}$. In addition to its oxidizing strength, the persulfate and sulfate radicals have several advantages over the other oxidant systems: (1) sulfate radicals are kinetically fast; (2) sulfate radicals are more stable and are able to transport efficiently on the solid surface compared to hydroxyl radicals; (3) Persulfate provides better acidic $\mathrm{pH}$, hence an efficient electron acceptor capable of accelerating the mineralization process. The sulfate radical anions produced in the case of APS show various possible reaction mechanisms in the process of mineralization: (1) abstraction of hydrogen atom from the saturated carbon; (2) ability to add itself to the unsaturated compounds; (3) removal of an electron from the anions and neutral molecules [16]. These attributes combine to make persulfate a viable option for the chemical oxidation of a broad range of contaminants. $0.5 \mathrm{ml}$ of $50 \% \mathrm{H}_{2} \mathrm{O}_{2}$ solution in $1 \mathrm{~L}$, resulting in $50 \mathrm{ppm}$, was used as stock solution. The influence of oxidants on the degradation was investigated by maintaining the other reaction parameters constant: It can be seen from Fig. $3(\mathrm{~A})$ that with an increase in the concentration of $\mathrm{H}_{2} \mathrm{O}_{2}$ (from 25 to $50 \mathrm{mg} / \mathrm{L}$ ), the decolorization efficiency increased from $58 \%$ to $100 \%$ in 90 min time duration under UV irradiation. On further increasing the concentration of $\mathrm{H}_{2} \mathrm{O}_{2}$, the efficiency of the process decreases due to the recombination of the excess hydroxyl radicals generated or these radicals might get involved in the unwanted reaction pathways. Similar experiments were carried with APS (50-200 mg/L), and its optimum concentration was found to be $100 \mathrm{mg} / \mathrm{L}$ (Fig. 3(B)). The reaction proceeds at a slower rate for APS in comparison with $\mathrm{H}_{2} \mathrm{O}_{2}$ which may be due to the difference in the reactivity of APS and $\mathrm{H}_{2} \mathrm{O}_{2}$ at the surface of ZVMI. Further sulfate radical being more stable compared to hydroxyl radical, its kinetics in attacking the organic molecule is slower. The excess acidity provided by the APS may lead to the oxidation of iron to $\mathrm{Fe}^{2+}$ ions which either act as hydroxyl radical quencher or precipitates as iron hydroxides which
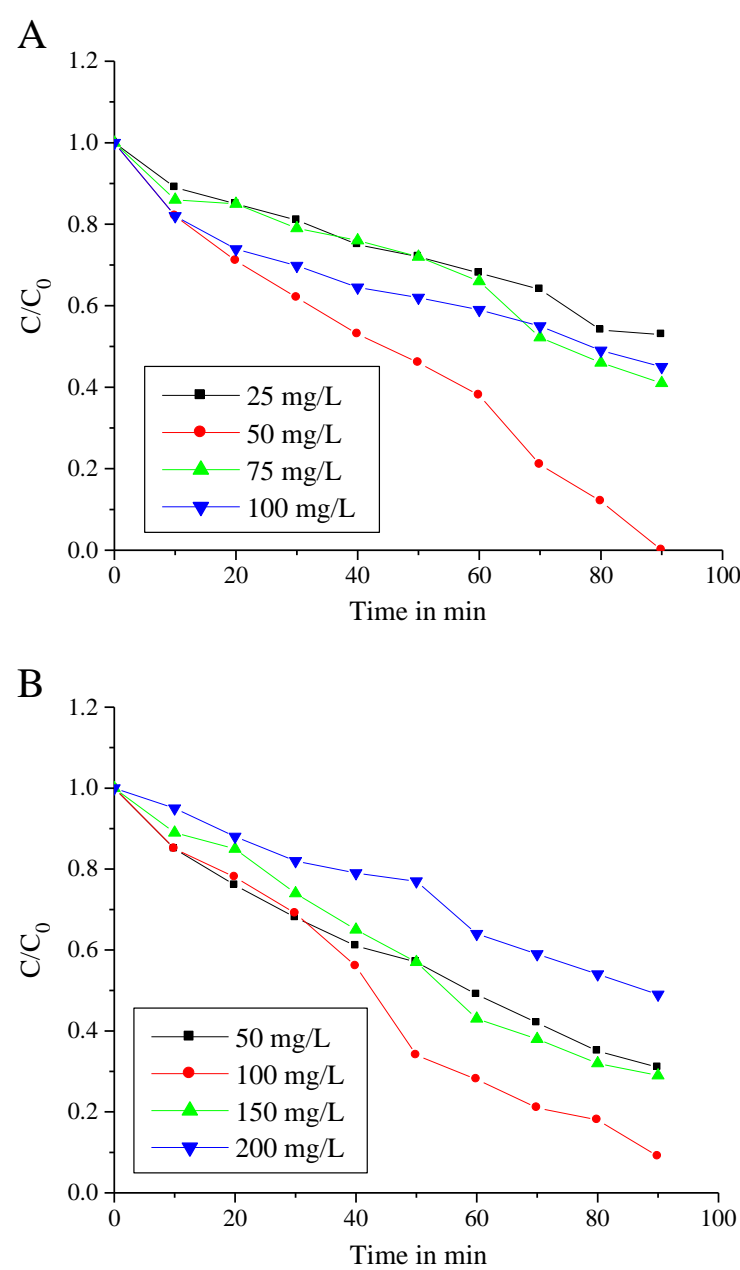

Fig. 3. Effect of concentration of HP (A)/Effect of concentration of APS (B) on the degradation of AR under optimized conditions of $\left[\mathrm{Fe}^{0}\right]=50 \mathrm{mg} / \mathrm{L},[\mathrm{AR}]=200 \mathrm{mg} / \mathrm{L}$ at $\mathrm{pH} 3$.

leads to the deactivation of iron surface. With subsequent runs, generation of hydroxyl radicals will be lowered.

\subsection{Effect of $p H$}

$\mathrm{pH}$ is an important parameter in the efficiency of the photo-Fenton process. It affects the rate of generation of hydroxyl radicals. Kang et al [23] reported that the pollutants can be decolorized efficiently by photo Fenton process only under acidic conditions. At $\mathrm{pH} 3$, the concentration of $\mathrm{Fe}^{3+}$ ions and $\mathrm{Fe}[\mathrm{OH}]^{2+}$ complexes are the two dominating photoactive species in almost equal proportions. The decrease in this optimum $\mathrm{pH}$ leads to decrease in the concentration of $\mathrm{Fe}[\mathrm{OH}]^{2+}$ complex ions and it can also result in the precipitation of ferrous ion as oxyhydroxides. The various photoactive species of iron formed at different $\mathrm{pH}$ conditions are: $\mathrm{Fe}\left[\mathrm{H}_{2} \mathrm{O}\right]_{6}^{3+}\left(\mathrm{pH} \mathrm{1-2)}\right.$, Fe $[\mathrm{OH}]\left[\mathrm{H}_{2} \mathrm{O}\right]_{5}^{2+}$ (pH 2-3) and $\mathrm{Fe}[\mathrm{OH}]_{2}\left[\mathrm{H}_{2} \mathrm{O}\right]_{4}^{+}$( $\mathrm{pH} \mathrm{3-4)}[2,8]$. The observed lower rate constant at very low $\mathrm{pH} 0.5$ is mainly due to the excess $\mathrm{H}^{+}$ions in the solution which acts as hydroxyl radical scavenger as shown in Eq. (15) in the Scheme 1 [21]. The change in the $\mathrm{pH}$ leads to the imbalance in the optimum concentration of $\mathrm{Fe}[\mathrm{OH}]^{2+}$ or it can lead to the precipitation of ferrous ions as oxyhydroxides. When the $\mathrm{pH}$ of the solution was increased from 3.0 to 9.0, degradation efficiency keeps decreasing as shown in Fig. 4. Further at higher $\mathrm{pH}$, the precipitate of iron oxyhydroxides deposits on the surface of iron powder preventing the process of further generation of hydroxyl radicals. This results in the coagulation of $\mathrm{Fe}^{3+}$ ions inhibiting the catalysis by $\mathrm{Fe}^{2+}$ ions. Therefore 


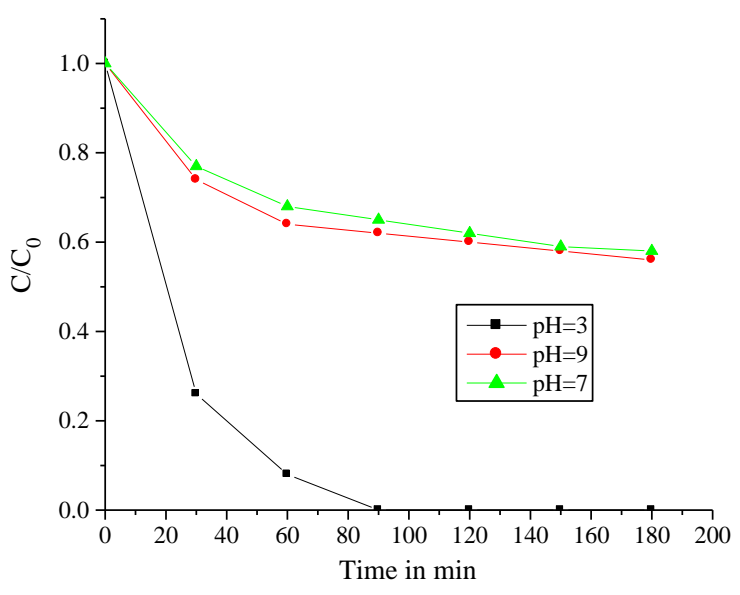

Fig. 4. The plot of $C / C_{0}$ versus time for the degradation of $A R$ under $U V$ illumination at different $\mathrm{pH}$ values under the experimental conditions of $\left[\mathrm{Fe}^{0}\right]=50 \mathrm{mg} / \mathrm{L},[\mathrm{AR}]=$ $200 \mathrm{mg} / \mathrm{L},[\mathrm{HP}]=50 \mathrm{mg} / \mathrm{L}$.

all the homogeneous and heterogeneous photo Fenton experiments were performed at $\mathrm{pH} 3$.

\subsection{Effect of aromatic derivatives on degradation reaction}

The specific reactions were carried out in the presence of aromatic and aliphatic derivatives. Among the various aromatic derivatives, $\mathrm{HQ}$ $\mathrm{RH}$ and $\mathrm{CH}$ shows enhancement in the degradation rate with the following order: $\mathrm{HQ}>\mathrm{RH}>\mathrm{CH}$. This is mainly due to the fact that hydroquinone has higher reducing capacity and it increases the concentration of $\mathrm{Fe}^{2+}$ ions in the solution which is most essential for the generation of hydroxyl radicals as shown in the following two steps [24]:<smiles>Oc1ccc(O)cc1</smiles>

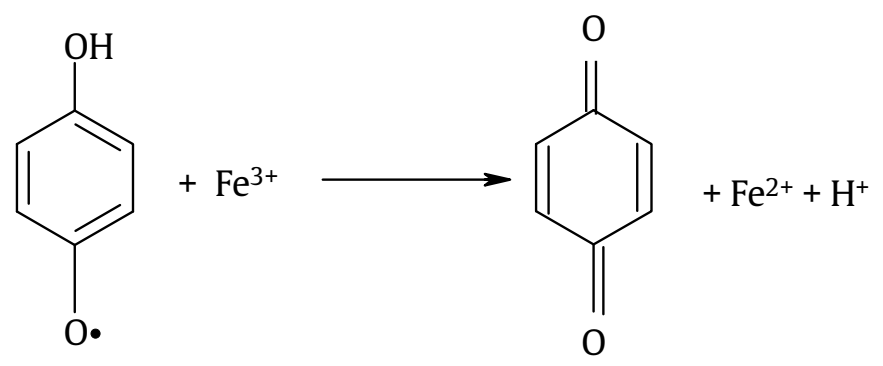

(18)

$\mathrm{RH}$ and $\mathrm{CH}$ showed lower rate compared to the $\mathrm{QH}$ probably due to the lower stability of these compounds due to stearic hindrance arising from the two $-\mathrm{OH}$ groups. $\mathrm{p}-\mathrm{CP}$ showed almost similar rate with that of controlled reaction ( the reaction in the absence of aromatic derivatives) for the first $20 \mathrm{~min}$ and later gets accelerated in the reaction rate. $\mathrm{p}-\mathrm{CP}$ gets transformed to $\mathrm{QH}$ like structure and catalyzes the photo Fenton reaction in the later stage of the reaction. By the attack of hydroxyl/ hydrogen radicals on $\mathrm{p}-\mathrm{CP}$, it might lose $-\mathrm{Cl}$ group as $\mathrm{HCl}$ and may get converted to $\mathrm{QH}$. The formation of $\mathrm{HCl}$ in the solution was noticed by slight decrease in the $\mathrm{pH}$ of the reaction medium from 3.0 to 2.6 which was not observed in the controlled reaction. p-DCB showed similar behavior but the reaction rate was slightly lower compared to $\mathrm{p}-\mathrm{CP}$ which may be due to the replacement of two $-\mathrm{Cl}$ groups by two $-\mathrm{OH}$ groups. The aromatic carboxylic acid derivatives like SA and PA showed slight enhancement in the degradation rate while $\mathrm{BA}$ inhibited the degradation rate compared to the controlled reaction. The acid group $(-\mathrm{COOH})$ needs to be hydroxylated before it participates in the photo Fenton reactions. The slight enhancement observed in the case of SA compared to PA can be accounted to the number of $-\mathrm{COOH}$ groups present in that particular aromatic carboxylic acid. As the number of $-\mathrm{COOH}$ groups increases the degradation rate decreases. BA was transformed to phenol, but the subsequent hydroxylation leads to quinhydrone like structure.

The $\mathrm{C}-\mathrm{Cl}$ bond is more susceptible to free radicals attack compared to $\mathrm{C}-\mathrm{C}$ bond. Hence slight enhancement in the degradation rate for aromatic chloro derivatives were observed compared to aromatic carboxylic acid derivatives. The protonation of $-\mathrm{NH}_{2}$ in $\mathrm{p}-\mathrm{AP}, \mathrm{AN}$ under photo Fenton conditions generates ammonium ion which is less likely to undergo electrophilic attack by the hydroxyl radicals and has lower tendency for transformation to HQ like structures. p-NP suppressed the degradation rate due to its inability to transform to $\mathrm{HQ}$. The aromatic derivative catalyzing the Fenton reactions shows the following order: $\mathrm{HQ}>\mathrm{RH}>\mathrm{CH}>\mathrm{p}-\mathrm{CP}>\mathrm{p}-\mathrm{DCB}>\mathrm{SA}>\mathrm{PA}>\mathrm{BA}>\mathrm{AN} \approx \mathrm{p}-$ $\mathrm{AP}>\mathrm{p}-\mathrm{NP}$. This order is in agreement with their tendency to transform to HQ like structure. The addition of OA (an aliphatic acid) enhances the ferrioxalate formation and also effectively reduces $\mathrm{Fe}^{3+}$ to $\mathrm{Fe}^{2+}$ ions enhancing the production of hydroxyl radicals, which accounts for the increase in the reaction rate compared to controlled reaction. However the addition of $\mathrm{MeOH} / \mathrm{i}-\mathrm{PrOH}$ which are well known as scavengers of hydroxyl radicals lowered the degradation rate [16,25]. Hence it can be concluded that aliphatic alcohols lowered the degradation efficiency while phenols enhanced the degradation efficiency. These results are shown in the Table 1 . The calculated rate constant value for the process $\mathrm{Fe}^{0} / \mathrm{H}_{2} \mathrm{O}_{2} / \mathrm{UV} / \mathrm{HQ}$ was 1.5 times higher than $\mathrm{Fe}^{0} / \mathrm{APS} / \mathrm{UV} / \mathrm{HQ}$. The controlled reaction of $\mathrm{Fe}^{0} / \mathrm{H}_{2} \mathrm{O}_{2} / \mathrm{UV}$ showed RH as the major intermediate along with SA as the minor photo product during the course of the reaction (The intermediates are further supported by the GC-MS analysis). The RH so formed can effectively reduce ferric ions thereby enhancing the concentration of ferrous ions in the solution. However no aromatic alcohols were detected as the intermediates for the process $\mathrm{Fe}^{0} / \mathrm{APS} / \mathrm{UV}$. Instead

Table 1

Rate constants for the processes $\mathrm{Fe}^{0} / \mathrm{H}_{2} \mathrm{O}_{2} / \mathrm{UV}$ and $\mathrm{Fe}^{0} / \mathrm{APS} / \mathrm{UV}$ in presence of various additives.

\begin{tabular}{llll}
\hline Aliphatic/aromatic derivatives & $\mathrm{Fe}^{0} / \mathrm{H}_{2} \mathrm{O}_{2} / \mathrm{UV}$ & \\
\cline { 2 - 3 } & $\mathrm{k} \cdot 10^{-2} \mathrm{~min}^{-1}$ & & $\mathrm{k} \cdot 10^{-2} \mathrm{~min}^{-1}$ \\
\hline- & 0.87 & 0.58 \\
$\mathrm{HQ}$ & 3.5 & 2.31 \\
$\mathrm{RH}$ & 2.46 & 1.95 \\
$\mathrm{CH}$ & 2.06 & 1.68 \\
$\mathrm{p}-\mathrm{CP}$ & 1.75 & 1.32 \\
$\mathrm{p}-\mathrm{AP}$ & 0.18 & 0.09 \\
$\mathrm{p}-\mathrm{NP}$ & 0.08 & 0.05 \\
$\mathrm{p}-\mathrm{DCB}$ & 1.37 & 0.98 \\
$\mathrm{AN}$ & 0.15 & 0.04 \\
$\mathrm{SA}$ & 1.07 & 0.75 \\
$\mathrm{PA}$ & 0.95 & 0.66 \\
$\mathrm{BA}$ & 0.42 & 0.38 \\
OA & 1.46 & 1.23 \\
$\mathrm{MeOH}$ & 0.52 & 0.38 \\
i-PrOH & 0.31 & 0.15 \\
\hline
\end{tabular}

Note : - indicates absence of additives. 
PA and benzene sulfonic acid were found as the major intermediates. Hence it can be concluded that aromatic photoproducts like RH, formed during the photo Fenton reactions significantly influences the degradation rate immaterial to the oxidant chosen, since in many of the reactions APS is also shown to be a better oxidant [10].

\subsection{Determination of COD and TOC analysis}

The complete mineralization of dyes has been followed by two techniques: The chemical oxygen demand (COD) and Total Organic Carbon (TOC) analysis. Both the techniques are complementary to one another for expressing the detoxification level of water. The COD analysis is given in Fig. 5(i). The COD was determined by using standard dichromate method [26], based on the following formula:

$\operatorname{COD}\left(\mathrm{O}_{2} \mathrm{mg} / \mathrm{L}\right)=\frac{\mathrm{V}_{\mathrm{o}}-\mathrm{V}_{1} \cdot \mathrm{N} \cdot 8 \cdot 1000}{\mathrm{~V}_{2}}$, where $\mathrm{N}$ is the concentration and $\mathrm{V}_{1}$ and $\mathrm{V}_{\mathrm{o}}$ are the volume of $\left(\mathrm{NH}_{4}\right)_{2}$ $\mathrm{Fe}\left(\mathrm{SO}_{4}\right)_{2}$ titrant in the experiment and in the blank titration. $\mathrm{V}_{2}$ is the volume of the water sample. Test samples were collected at every 15 min time interval. The percentage of COD removal is calculated using the formula:

Percentage of COD removal $:=\left[\frac{\mathrm{COD}_{\text {Blank sample }}-\mathrm{COD}_{\text {AR sample }}}{\mathrm{COD}_{\text {Blank sample }}}\right] \cdot 100$

Percentage COD removal efficiency for the process $\mathrm{Fe}^{0} / \mathrm{H}_{2} \mathrm{O}_{2} / \mathrm{UV}$ and $\mathrm{Fe}^{0} / \mathrm{APS} / \mathrm{UV}$ in the presence of various aromatic derivatives shows that degradation rate is strongly dependent on the additive added. Highest enhancement in the degradation rate was observed for $\mathrm{HQ}$ followed by $\mathrm{CH}$ and $\mathrm{RH}$. This is mainly due to the fact that $\mathrm{HQ}$ in the solution directly reduces $\mathrm{Fe}^{3+}$ to $\mathrm{Fe}^{2+}$ ions thereby enhancing the concentration of $\mathrm{Fe}^{2+}$ ions in the solution which is most essential for the generation of hydroxyl radicals. The least COD removal was observed in the presence of AN as
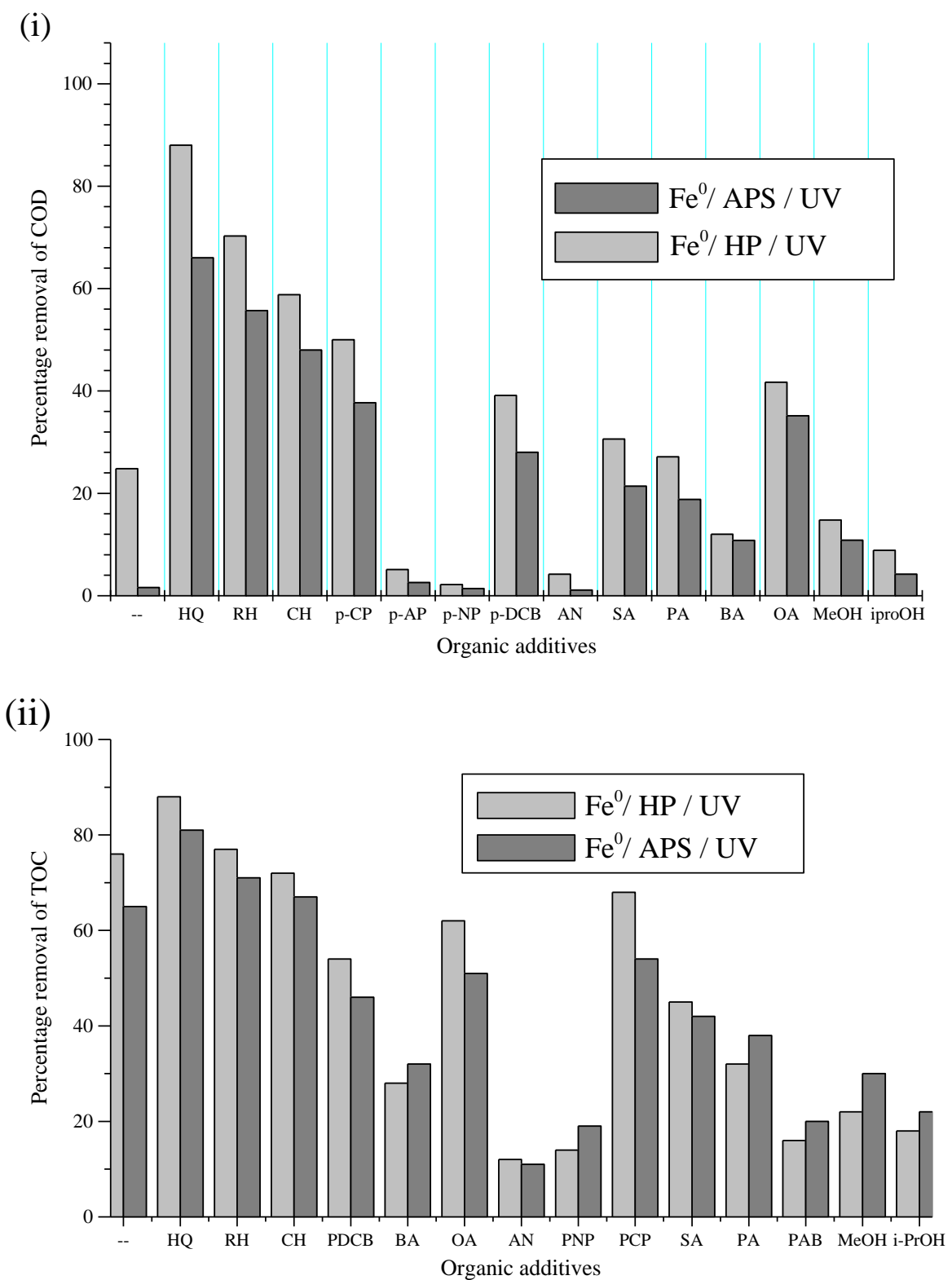

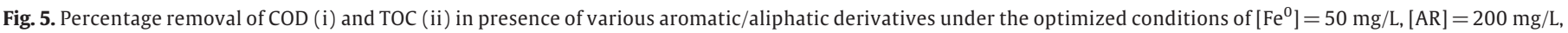
$[\mathrm{HP}]=50 \mathrm{mg} / \mathrm{L} /[\mathrm{APS}]=100 \mathrm{mg} / \mathrm{L}$ at $\mathrm{pH} 3$. 
shown in Fig. 5(i) and it shows the following order: $\mathrm{HQ}>\mathrm{RH}>\mathrm{CH}>\mathrm{p}-$ $\mathrm{CP}>\mathrm{OA}>\mathrm{p}-\mathrm{DCB}>\mathrm{SA}>\mathrm{PA}>\mathrm{MeOH}>\mathrm{BA}>\mathrm{i}-\mathrm{PrOH}>\mathrm{AN}>\mathrm{p}-\mathrm{AP}>\mathrm{p}-\mathrm{NP}$.

TOC analysis of AR in the $\mathrm{Fe}^{0} / \mathrm{H}_{2} \mathrm{O}_{2} / \mathrm{UV}$ and $\mathrm{Fe}^{0} / \mathrm{APS} / \mathrm{UV}$ processes along with the various aliphatic/aromatic additives are illustrated in Fig. 5 (ii). It is observed that the percentage removal of TOC in the presence of $\mathrm{HQ}, \mathrm{CH}$ and $\mathrm{RH}$ was faster than the other additives and it shows the following order: $\mathrm{HQ}>\mathrm{RH}>\mathrm{CH}>\mathrm{p}-\mathrm{CP}>\mathrm{OA}>\mathrm{p}-$ $\mathrm{DCB}>\mathrm{SA}>\mathrm{PA}>\mathrm{BA}>\mathrm{MeOH}>\mathrm{p}-\mathrm{AP}>\mathrm{i}-\mathrm{PrOH}>\mathrm{p}-\mathrm{NP}>\mathrm{AN}$. Two possible scenarios may explain this observation; the first is that the variation in the dynamics might reflect difference in the nature and formation of intermediates. The second possibility might be strongly dependent on the organic additive added. Highest removal rate is observed in the presence of $\mathrm{HQ}, \mathrm{CH}$ and $\mathrm{RH}$ compared to other additives. This is due to the production of higher concentration of $\mathrm{Fe}^{2+}$ ions in these particular cases which is essential for the generation of hydroxyl radicals. TOC disappearance pattern in $5 \mathrm{~h}$ time duration is shown in Fig. 5 (ii). It is generally accepted that the aliphatic and aromatic moieties are successively attacked by the photogenerated hydroxyl radicals. This leads to various hydroxylated intermediates before the ring opening. The above reactions can be termed as "Photo Kolbe" reactions in which carboxylic intermediates undergo further mineralization [27]. From the toxicological point of view, TOC analysis seems to be accurate and appropriate for evaluating the decontamination of polluted water containing organics, since it takes in to account all the residual carbon-containing molecules.

\subsection{Kinetics studies}

The dye solution was decolorized to an extent of 6,10 and $18 \%$ for the experiments $\mathrm{Fe}^{0} /$ dark (A), $\mathrm{Fe}^{0} / \mathrm{APS} /$ dark (B) and $\mathrm{Fe}^{0} / \mathrm{H}_{2} \mathrm{O}_{2} /$ dark (C) processes respectively in 90 min duration ( Fig. 6 and Table 2). The dye decolorization in the presence of $\mathrm{Fe}^{0} /$ dark is due to the formation of iron complexes due to the reaction of iron ions with the dye molecules preferably with the chromophore of AR [25]. The presence of oxidants like $\mathrm{H}_{2} \mathrm{O}_{2}$ /APS increases the decolorisation efficiency compared to the $\mathrm{Fe}^{\mathrm{O}}$ /dark process. Iron powder under acidic condition gets oxidized to $\mathrm{Fe}^{2+}$ ions (Eq. (2), Scheme 1), which further reacts with $\mathrm{H}_{2} \mathrm{O}_{2}$ /APS to generate hydroxyl radicals as shown by the Eqs. (3) to (14) in Scheme 1. In the presence of oxidants alone (in the dark condition), dye decolorisation was almost negligible. On UV irradiation for $90 \mathrm{~min}$, the decolorisation efficiency for the process $\mathrm{D}, \mathrm{E}$ and $\mathrm{F}$ (Fig. 6) increased up to 22,48 and $78 \%$ respectively. The enhancement in the efficiency of $\mathrm{Fe}^{0} / \mathrm{UV}$ process is due to the fact that iron complexes formed in the dark can be destroyed under UV irradiation and the iron ions can return to iron regeneration cycle for active

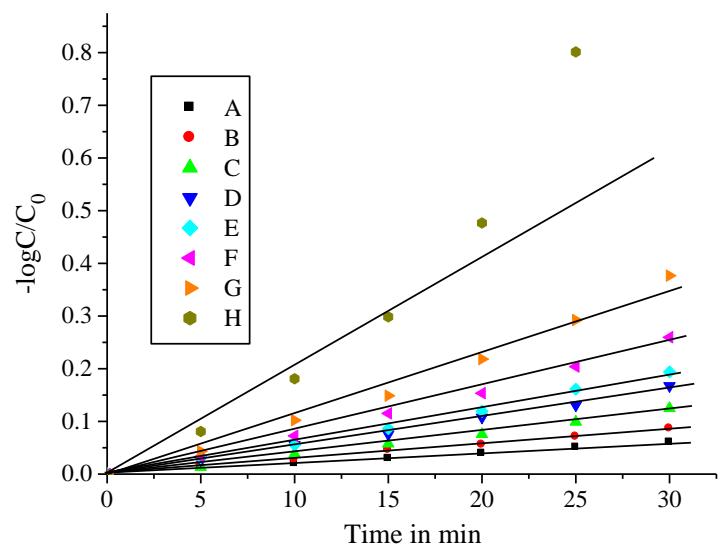

Fig. 6. Plot of $-\log C / C_{0}$ versus time for the degradation of $A R$ using various oxidation processes. (A) $\mathrm{Fe}^{0} /$ dark (B) $\mathrm{Fe}^{0} / \mathrm{APS} /$ dark (C) UV/APS (D) $\mathrm{Fe}^{0} / \mathrm{H}_{2} \mathrm{O}_{2} /$ dark (E) $\mathrm{Fe}^{0} / \mathrm{UV}$ (F) UV/ $\mathrm{H}_{2} \mathrm{O}_{2}$ G) $\mathrm{Fe}^{0} / \mathrm{APS} / \mathrm{UV}$ and $\mathrm{H}$ ) $\mathrm{Fe}^{0} / \mathrm{H}_{2} \mathrm{O}_{2} / \mathrm{UV}$ under optimized conditions $\left[\mathrm{Fe}^{0}\right]=50 \mathrm{mg} / \mathrm{L},[\mathrm{AR}]=200 \mathrm{mg} / \mathrm{L},\left[\mathrm{H}_{2} \mathrm{O}_{2}\right]=50 \mathrm{mg} / \mathrm{L} /[\mathrm{APS}]=100 \mathrm{mg} / \mathrm{L}$ at $\mathrm{pH} 3$.
Table 2

Percentage degradations, rate constant and process efficiency for the degradation of AR using various oxidation processes.

\begin{tabular}{|c|c|c|c|}
\hline \multirow[t]{2}{*}{ Oxidation Processes } & \multirow[t]{2}{*}{ Percentage degradation } & \multirow{2}{*}{$\begin{array}{l}* \\
\mathrm{k} \cdot 10^{-2} \\
\left(\min ^{-1}\right)\end{array}$} & \multirow{2}{*}{$\begin{array}{l}\text { *** } \\
(\Phi) \cdot 10^{-12} \\
\left(\mathrm{ppm} \text { Einstein }{ }^{-1}\right)\end{array}$} \\
\hline & & & \\
\hline UV/APS & 15 & 0.05 & 1.81 \\
\hline $\mathrm{UV} / \mathrm{H}_{2} \mathrm{O}_{2}$ & 26 & 0.11 & 3.14 \\
\hline $\mathrm{Fe}^{0} /$ dark & 6 & 0.07 & $2.17 a$ \\
\hline $\mathrm{Fe}^{0} / \mathrm{APS} / \mathrm{dark}$ & 10 & 0.11 & $3.14 \mathrm{a}$ \\
\hline $\mathrm{Fe}^{0} / \mathrm{H}_{2} \mathrm{O}_{2} /$ dark & 18 & 0.19 & $4.59 a$ \\
\hline $\mathrm{Fe}^{0} / \mathrm{UV}$ & 22 & 0.19 & 4.47 \\
\hline $\mathrm{Fe}^{0} / \mathrm{APS} / \mathrm{UV}$ & 48 & 2.23 & 8.95 \\
\hline $\mathrm{Fe}^{0} / \mathrm{H}_{2} \mathrm{O}_{2} / \mathrm{UV}$ & 78 & 3.64 & 12.1 \\
\hline
\end{tabular}

* Plot of negative $\log \mathrm{C} / \mathrm{C}_{0}$ versus time for the degradation of $\mathrm{AR}$ using various oxidation processes gives the striate line (As shown in Fig. 5) slope of the striate line gives the rate of the degradation i.e., Slope $=\mathrm{k}=\frac{\mathrm{dc}}{\mathrm{dt}}$ where $\mathrm{dc}$ is the change in the concentration of $\mathrm{AR}$ in $\mathrm{mg} / \mathrm{L}$ at time interval ' $\mathrm{dt}$ ' sec. using this method we calculated the rate constant $\mathrm{k}$. ** The Process efficiency $(\Phi)$ is defined as the 'change in concentration divided by the amount of energy in terms of intensity and exposure surface area per time' i. e., $\Phi=\frac{C_{0}-C}{\text { tIS }}$ Where $C_{0}$ is the initial concentration of the substrate and $C$ is the concentration at time ' $\mathrm{t}$ '. $\left(\mathrm{C}_{0}-\mathrm{C}\right)$ denotes the residual pollutant concentration in $\mathrm{mg} \mathrm{L}^{-1}$ or ppm. 'I' is the irradiation intensity. ' $\mathrm{S}$ ' denotes the solution irradiated plane surface area in $\mathrm{cm}^{2}$ and ' $\mathrm{t}$ ' represents the irradiation time in minutes. Process efficiency $(\Phi) \cdot 10^{-12}$ in UV illumination is expressed in ppm Einstein ${ }^{-1}$.

a Process efficiency in dark process is expressed as ppm.

participation in the cyclic photo Fenton process. The generation of hydroxyl radicals by the oxidants alone and the photolysis of dye molecules additionally contribute to the overall enhancement in the decolorization process. In addition, photo reduction of $\mathrm{Fe}^{3+}$ to $\mathrm{Fe}^{2+}$ ions takes place at a faster rate on the iron surface in APFP. The rate constant for the kinetics of decolorization for various oxidation processes is of the order: $\mathrm{Fe}^{0} /$ dark $<\mathrm{Fe}^{0} / \mathrm{APS} /$ dark $<\mathrm{UV} / \mathrm{APS}<\mathrm{Fe}^{0} /$ $\mathrm{H}_{2} \mathrm{O}_{2} /$ dark $<\mathrm{Fe}^{0} / \mathrm{UV}<\mathrm{UV} / \mathrm{H}_{2} \mathrm{O}_{2}<\mathrm{Fe}^{0} /$ APS $/ \mathrm{UV}<\mathrm{Fe}^{0} / \mathrm{H}_{2} \mathrm{O}_{2} / \mathrm{UV}$. The rate constant and process efficiency values for the above oxidation processes are shown in the Table 2 .

\subsection{GC-MS analysis}

\subsubsection{The degradation mechanism in $\mathrm{Fe}^{0} / \mathrm{H}_{2} \mathrm{O}_{2} / \mathrm{UV}$ process}

The GC-MS analysis for the experiment $\mathrm{Fe}^{0} / \mathrm{H}_{2} \mathrm{O}_{2} / \mathrm{UV}$ which showed highest rate constant and process efficiency is shown in Fig. 7(i). The degradation intermediates were identified by this technique. Very low intensity peaks were left unidentified. The sample before UV irradiation shows two $\mathrm{m} / \mathrm{z}$ peaks at 604 of high intensity corresponding to the parent dye molecule and $\mathrm{m} / \mathrm{z}$ peak of medium intensity at 538 attributed to the ionized dye molecule (Fig. 7 (i) A). The sample after $10 \mathrm{~min}$ of irradiation showed two $\mathrm{m} / \mathrm{z}$ peaks. A high intensity peak at 159 and a lower intensity $\mathrm{m} / \mathrm{z}$ peak at 172 (Fig. 7 (i) B) corresponding to 4-amino, hydroxynapthalene (2) and 1amino, 2 (2, 4 dihydroxyphenyl) ethanoic acid (3). This implies that the azo form of AR tautomerizes to hydrazone form and it cleaves in presence of $\mathrm{Fe}^{0} / \mathrm{OH}^{*}$ (as shown in Scheme 2) which is also supported by the previous reports $[28,29]$. The sample after $30 \mathrm{~min}$ of irradiation showed $\mathrm{m} / \mathrm{z}$ peaks at 160 (4-hydroxynapthalene (4)), 158 (naphthoquinone (6)) and a medium intensity peak at 110 (Resorcinol (5)) as show in Fig. 7(i) C. These are formed by the attack of hydroxyl radical at amino group of intermediate (2) and cleavage of 1-aminoethanoic acid from the molecule (3). After $45 \mathrm{~min}$ of irradiation the formation of high intensity $\mathrm{m} / \mathrm{z}$ peaks at 138, 104, 90 and 46 (Fig. 7(i) D) corresponds to Salicylic acid (7), malonic acid (8), oxalic acid (9) and formic acid (10) respectively. Based on the intermediates obtained, probable degradation mechanism has been proposed as shown in Scheme 2. 
A

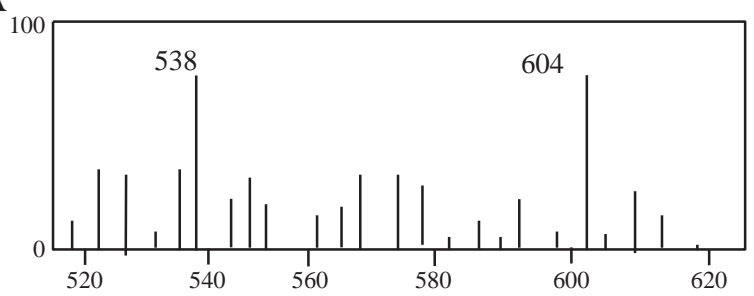

B

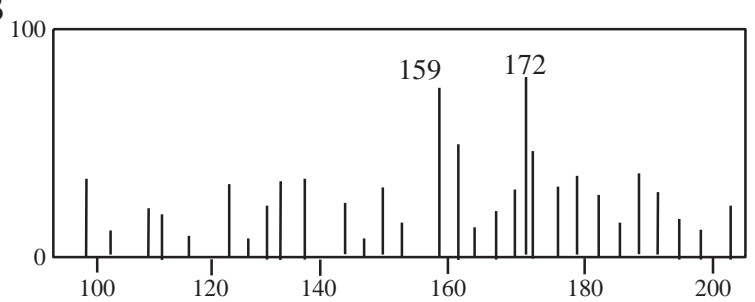

$\mathrm{C}_{100}$

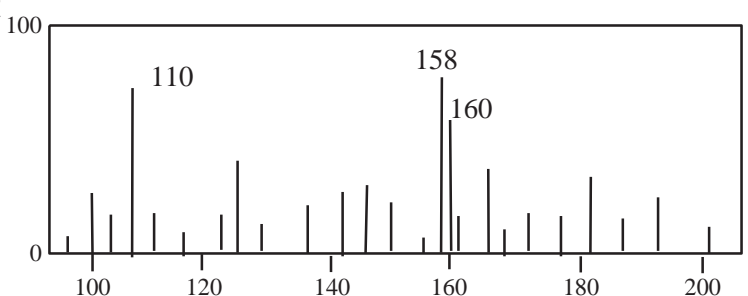

$\mathrm{D}_{100}$

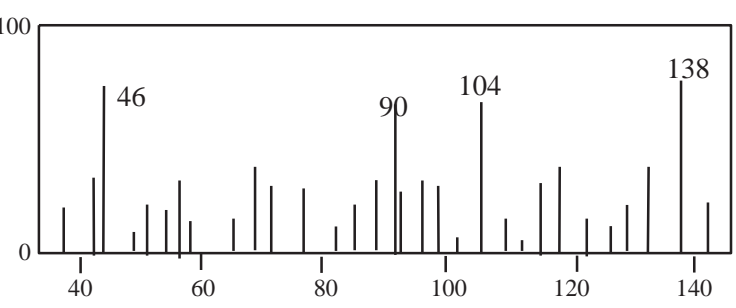

(i)
A

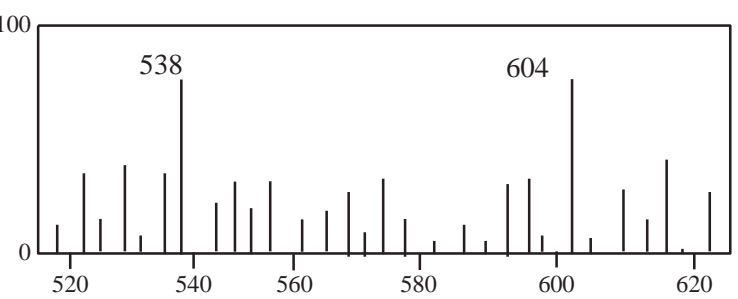

$\mathrm{B}$

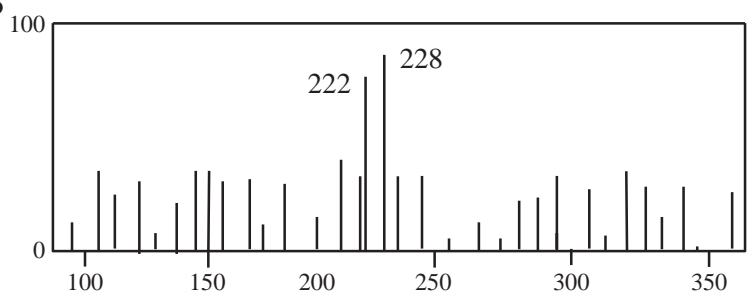

$\mathrm{C}_{100}$

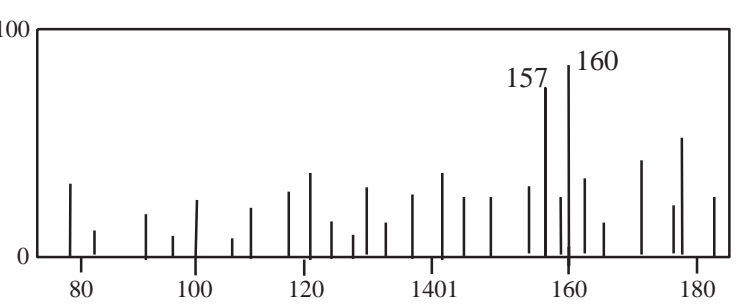

$\mathrm{D}_{100}$

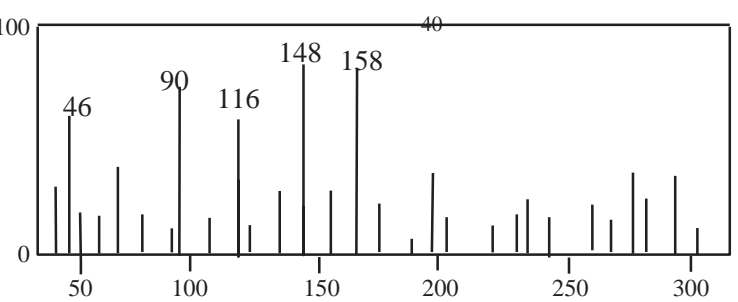

(ii)

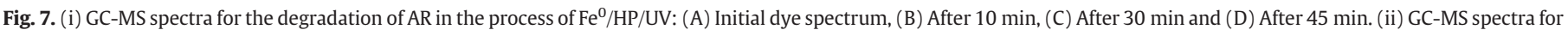

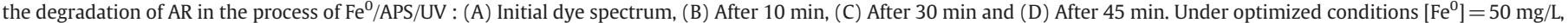
$[A R]=200 \mathrm{mg} / \mathrm{L},[\mathrm{HP}]=50 \mathrm{mg} / \mathrm{L},[$ APS $]=100 \mathrm{mg} / \mathrm{L}$ and at $\mathrm{pH} 3$.

\subsubsection{The degradation process in $\mathrm{Fe}^{0} / \mathrm{APS} / \mathrm{UV}$}

The GC-MS analysis for the experiment $\mathrm{Fe}^{0} / \mathrm{APS} / \mathrm{UV}$ is shown in the Fig. 7(ii). The sample after $10 \mathrm{~min}$ of irradiation showed a high intensity $\mathrm{m} / \mathrm{z}$ peak at 222 and a medium intensity $\mathrm{m} / \mathrm{z}$ peak at 228 (Fig. 7(ii) B) corresponding to 4-amino, napthalenesulphonic acid (11) and 1-amino, 2 (4 benzensulphonyl) ethanoic acid (12). This implies the formation of hydrazone form of AR and it cleaves in the presence of $\mathrm{Fe}^{0} / \mathrm{OH}^{\cdot} / \mathrm{SO}_{4}^{-}$(as shown in Scheme 3). The sample after $30 \mathrm{~min}$ of irradiation showed $\mathrm{m} / \mathrm{z}$ peaks at 160 and 157 of medium intensity (Fig. 7(ii) C) corresponding to 4-hydroxynapthalene (4) and Benzenesulfonic acid (13) which are formed by the attack of hydroxyl radical at amino and sulfonic group of intermediate (11) and cleavage of 1-amino ethanoic acid from the molecule (12). After $45 \mathrm{~min}$ of irradiation the formation of high intensity $\mathrm{m} / \mathrm{z}$ peaks at $158,148,116$, 90 and 46 (Fig. 7(ii) D) corresponds to naphthoquinone (6), pthalic acid (14), maleic acid (15), oxalic acid (9) and formic acid (10) respectively. The formation of pthalic acid during the degradation of AR is in agreement with the previous reports [27]. Based on the intermediates obtained, probable degradation mechanism has been proposed as shown in Scheme 3.

\section{Conclusions}

The photo Fenton degradation of AR was carried out by using ZVMI as the catalyst along with symmetrical peroxides as the oxidants. The influence of various reaction parameters like effect of iron dosage, concentration of $\mathrm{H}_{2} \mathrm{O}_{2}$ /APS, initial dye concentration, effect of $\mathrm{pH}$ and the influence of various aromatic derivatives were studied and optimum conditions are reported. It was found that aromatic photo products formed during the course of the reaction had a profound effect on the degradation rate. Therefore the degradation was performed under the influence of various aliphatic/aromatic derivatives. It was found that aromatic alcohols enhanced the degradation rate while aliphatic alcohols lowered the rate of degradation. The enhancement in the rate was mainly attributed to the ability of aromatic derivatives to reduce ferric ions. The percentage of COD and TOC removal was determined in presence of aromatic derivatives to evaluate the complete removal of the pollutant. Photoproducts were analyzed based on the GC-MS technique and a probable reaction mechanism has been proposed. 


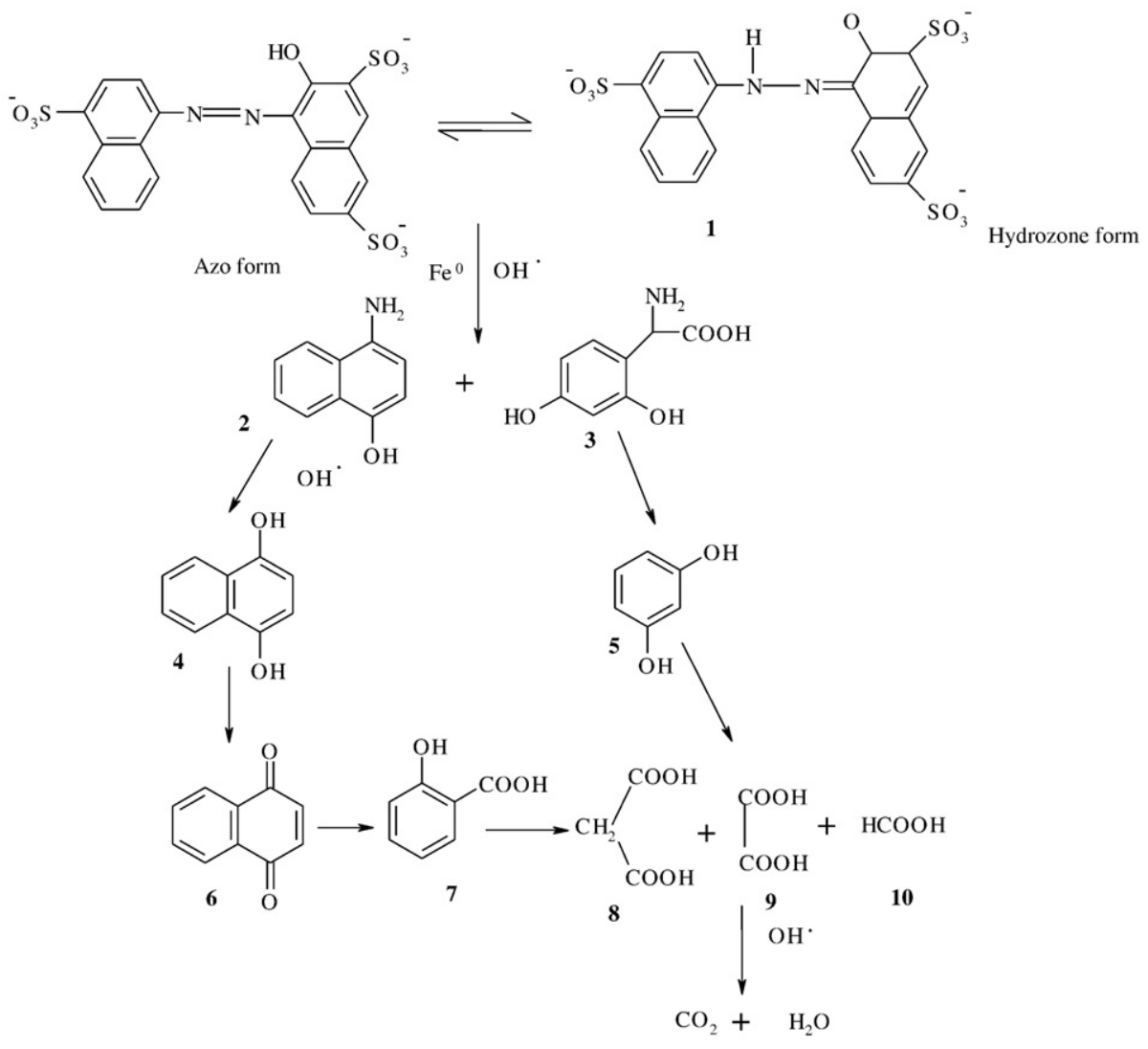

Scheme 2. Probable degradation mechanism of AR under the process of $\mathrm{Fe}^{0} / \mathrm{UV} / \mathrm{HP}$.

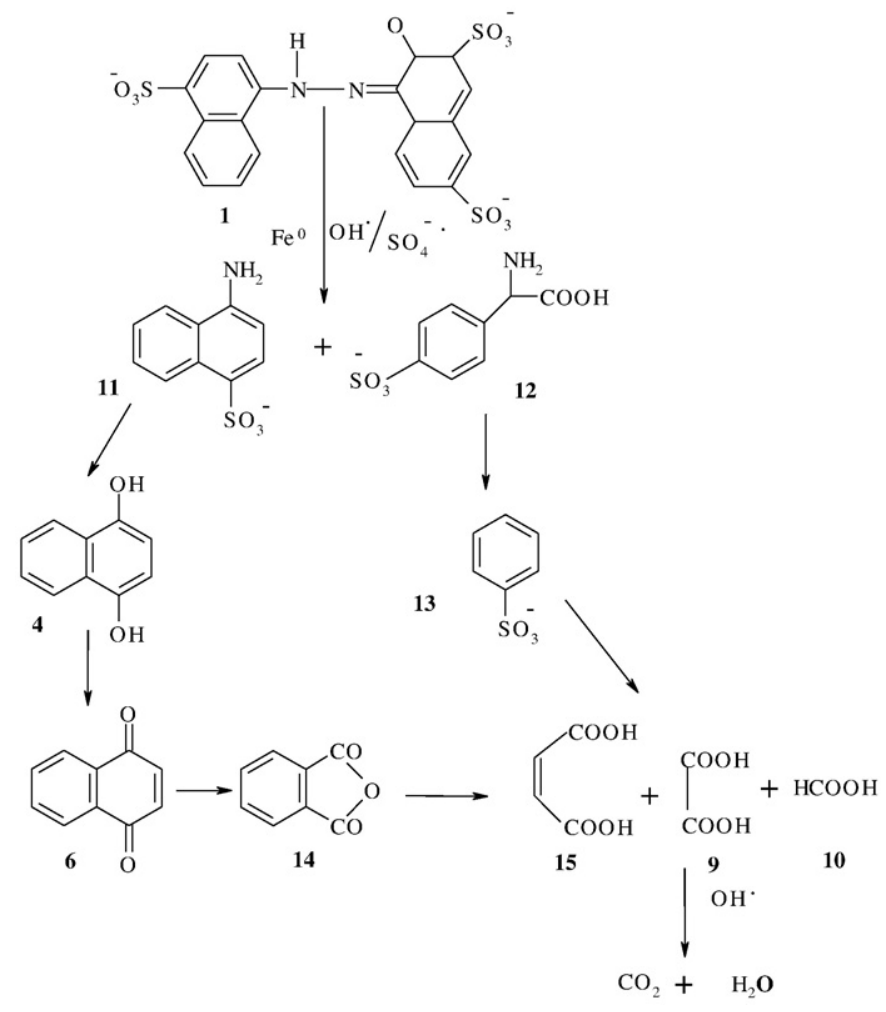

Scheme 3. Probable degradation mechanism of AR under the process of $\mathrm{Fe}^{0} / \mathrm{UV} / \mathrm{APS}$.

\section{Acknowledgements}

Financial support from UGC and DST Major Research Project is acknowledged.

\section{References}

[1] J.N. Fiedor, W.D. Bostick, R.J. Jarabek, J. Farrell, Understanding the mechanism of uranium removal from groundwater by zerovalent iron using X-ray photoelectron spectroscopy, Environmental Science and Technology 32 (1998) 1466-1473.

[2] G.R. Eykholt, D.T. Davenport, Dechlorination of the chloroacetanilide herbicides alachlor and metolachlor by iron metal, Environmental Science and Technology 32 (1998) 1482-1487.

[3] C.P. Huang, H.W. Wang, P. Chunchiu, Nitrate reduction by metallic iron, Water Research 32 (1998) 2257-2264.

[4] C. Ruangchainikom, C.H. Liao, J. Anotai, M.T. Lee, Characteristics of nitrate reduction by zero-valent iron powder in the recirculated and $\mathrm{CO}_{2}$-bubbled system, Water Research 40 (2006) 195-204.

[5] R. Venkatpathy, D.G. Bessingpas, S. Canonica, J.A. Perlinger, Kinetics models for trichloroethylene transformation by zero-valent iron, Applied Catalysis B: Environmental 37 (2002) 139-159.

[6] A. Agarwal, P.G. Tratneyk, Reduction of nitro aromatic compounds by zero-valent iron metal, Environmental Science and Technology 30 (1996) 153-160.

[7] K. Ntampegliotis, A. Riga, V. Karayannis, V. Bontozoglou, G. Papapolymerou, Decolorization kinetics of Procion H-exl dyes from textile dyeing using Fentonlike reactions, Journal of Hazardous Materials 136 (2006) 75-84.

[8] M. Neamtu, A. Yediler, I. Siminiceanu, A. Kettrup, Oxidation of commercial reactive azo dye aqueous solutions by the photo-Fenton and Fenton-like process, Journal of Photochemistry Photobiology A: Chemical 161 (2003) 87-93.

[9] L. Gomathi Devi, S. Girish Kumar, K.S. Anantha Raju, K. Eraiah Rajashekhar, PhotoFenton and photo-Fenton-like processes for the degradation of methyl orange in aqueous medium: influence of oxidation states of iron, Chemical Papers 64 (2010) 378-385.

[10] L. Gomathi Devi, K.E. Rajashekhar, K.S. Anantha Raju, S. Girish Kumar, Kinetic modeling based on the non-linear regression analysis for the degradation of Alizarin Red S by advanced photo Fenton process using zero valent metallic iron as the catalyst, Journal of Molecular Catalysis A: chemical 314 (2009) 88-94.

[11] C.L. Hsueh, Y.H. Huang, C.C. Wang, C.Y. Chen, Degradation of azo dyes using low Fe concentration of Fenton and Fenton-like system, Chemosphere 58 (2005) 1409-1414. 
[12] C. Pulgarin, P. Peringer, P. Albers, J. Kiwi, Effect of Fe-ZSM-5-Zeolite on the photo chemical and biochemical degradation of 4-nitrophenol, Journal of molecular catalysis A: chemical 95 (1995) 61-74.

[13] R. Matta, K. Hanna, S. Chiron, Fenton like oxidation of 2,4,6 Trinitrotoluene using different minerals, Science of the Total Environment 385 (2007) 242-251.

[14] J. Lei, C. Liu, F. Li, X. Li, S. Zhou, T.X. Liu, M. Gu, Q. Wu, Photodegradation of orange I in the heterogeneous iron oxide-oxalate system under UVA irradiation, Journal of Hazardous Materials 137 (2006) 1016-1024.

[15] F. Lucking, H. Koser, M. Jank, A. Ritter, Iron powder and graphite and activated carbon as a catalyst for the oxidation of 4-chlorophenol with hydrogen peroxide in aqueous solution, Water Research 32 (1998) 2607-2614.

[16] L.G. Devi, S.G. Kumar, K.M. Reddy, C. Munikrishnappa, Photodegradation of Methyl Orange an Azo dye by Advanced Fenton Process using zero valent metallic iron:Influence of various reaction parameters and its degradation mechanism, Journal Hazardous Materials 164 (2009) 459-467.

[17] D.H. Bremner, A.E. Burgess, D. Houllemare, K.C. Namkung, Phenol degradation by using hydroxyl radicals generated from zero-valence iron and hydrogen peroxide, Applied Catalysis B: Environomental 63 (2006) 15-19.

[18] G.A. Hamilton, J.W. Hanifin, J.P. Friedman, The hydroxylation of aromatic compounds by hydrogen peroxide in the presence of catalytic amounts of ferric ion and catechol. product studies, mechanism, and related to some enzymic reactions, Journal American Chemical Society 88 (1966) 5269-5272.

[19] R.Z. Chen, J.J. Pignatello, Role of quinone intermediate as electron shuttles in fenton and photoassited fenton oxidation of aromatic compounds, Environmental Science and Technology 31 (1997) 2399-2406.

[20] M.E. Balmer, B. Sulzberger, Atrazine degradation in irradiated iron/oxalate system: effect of pH and oxalate, Environmental Science Technology 33 (1999) 2418-2424.
[21] K. Barbusinski, J. Majewski, Degradation of azo dye acid 18 by Fenton reagent in the presence of iron powder, Polish Journal of Environmental Studies 12 (2003) $151-155$.

[22] O.S.N. Sum, J. Feng, X. Hu, P.L. Yue, Photo assisted Fenton mineralization of an azo dye acid black 1 using a modified laponite clay based Fe nano composite as a heterogeneous catalysts, Topics in Catalysis 33 (2005) 233-242.

[23] S.F. Kang, C.H. Liao, M.C. Chen, Treatment of 2-phenylamino-3-methyl-6-di- $n$ butylaminofluoran production effluent by combination of biological treatments and Fenton's oxidation, Chemosphere 46 (2002) 923-928.

[24] F. Chen, J. He, J. Zhao, J.C. Yu, Photo-Fenton degradation of malachite green catalyzed by aromatic compounds under visible light irradiation, New Journal of Chemistry 26 (2002) 336-341.

[25] W. Choi, H. Park, Visible light and Fe(III)-mediated degradation of Acid Orange 7 in the absence of $\mathrm{H}_{2} \mathrm{O}_{2}$, Journal of Photochemistry Photobiology A: Chemistry 159 (2003) 241-247.

[26] L.G. Devi, K.M. Reddy, Enhanced photocatalytic activity of silver metallized $\mathrm{TiO}_{2}$ particles in the degradation of an azo dye methyl orange: characterization and activity at different pH values, Applied Surface Science 256 (2010) 3116-3121.

[27] B. Krautler, A.J. Bard, Heterogeneous photocatalytic synthesis of methane from acetic acid-new Kolbe reaction pathway, Journal of American Chemical Society 100 (1978) 2239-2240.

[28] C. Bauer, P. Jacques, A. Kalt, Investigation of the interaction between a sulfonated azo dye (AO7) and a $\mathrm{TiO}_{2}$ surface, Chemical Physics Letters 307 (1999) 397-406.

[29] M. Karkmaz, E. Puzenat, C. Gillard, J.M. Hermann, Photocatalytic degradation of the alimentary azo dye amaranth mineralization of the azo group to nitrogen, Applied Catalysis B: Environmental 51 (2004) 183-194. 